\title{
Design of Pattern Reconfigurable Linear Array Antenna for Multi-band Application
}

\author{
D.Rama Krishna ${ }^{1, *}$, V.M.Pandharipande ${ }^{2}$ \\ ${ }^{1}$ Department of ECE,Osmania University,Hyderabad-500007,India \\ ${ }^{2}$ Dr.Babasaheb Ambedkar Marathwada University,Aurangabad-431004,India \\ *Corresponding Author: dasariramakrishna@yahoo.com
}

Copyright (C) 2013 Horizon Research Publishing All rights reserved.

\begin{abstract}
The design of Tri-Band, 1X8 Linear Antenna Array that operates in three bands $5.4 \mathrm{GHz}, 6.2 \mathrm{GHz}, 9.2 \mathrm{GHz}$ with the perspective that the antenna array has multiple resonating frequencies and is able to modify its radiation pattern as well, using Micro-strip Patch Antenna elements in combination with PIN Diodes and beam can be steered in each iteration by controlling the supply of PIN Diodes.
\end{abstract}

Keywords Tri-band, Rectangular Reconfigurable, Phased Array

\section{Introduction}

Reconfigurable antenna arrays that are capable of resonating at multiple frequencies and radiating multiple patterns using a single feeder network are desirable in many applications [1-5]. Present antenna requirement for fighter aircraft is that single antenna for navigation, communication and combat applications. Envisaging this requirement this work has been carried out. This linear array has the capable of resonating at $5.4 \mathrm{GHz}$ where $802.11 \mathrm{a}$ Wi-Fi networks, Wireless LAN and cordless telephone applications works, $6.2 \mathrm{GHz}$ where satellite uplink communication works and at 9.2 GHz where Airborne RADAR applications are found. The current planar phased array technology is typically limited in both scan angle and frequency bandwidth as a result of the limitations of the individual array elements and the effects of antenna element spacing. Many of these established applications assume that the antenna element pattern is fixed, all of the elements are identical, and the elements lie on a periodic grid. The addition of reconfigurability to antenna arrays can provide additional degrees of freedom that may result in wider instantaneous frequency bandwidths, more extensive scan volumes, and radiation patterns with more desirable side lobe distributions In large phased arrays, reconfigurable antennas could be used to provide additional capabilities that may result in wider instantaneous frequency bandwidths, more extensive scan volumes, and radiation patterns with more desirable side lobe distributions[6-8]. Integrating phase shifts into array element reconfigurability can result in beam steering similar to that achieved with traditional phased arrays but without the inherent costs of phase shifters. In this work, an electronically scanned array uses reconfigurable microstrip patch antenna elements to vary the phase across the array.

\section{Technical Approach}

This linear array has been designed and simulated in Agilent ADS. In the Development stage,1X8 Linear Array has been fabricated using photo lithography technique in RT Duroid 5880 Substrate $(\varepsilon r=2.2)$ and $\operatorname{Tan} \delta=0.0009$. The individual element consists of 9 rectangular patch elements in the same substrate. The connection between one elements to the other is achieved by switching of PIN Diodes. In this work, we use 8 nos. of PIN Diodes for each antenna element as the controlling elements for making connections between the rectangular patches. As the size of the PIN Diode is so small $(1 \mathrm{~mm})$, gold ribbons are used to connect the PIN Diodes with the rectangular elements. The excitation of the each element is achieved using SMA connector. The PIN Diodes are driven by a separate 'driver' circuit. By controlling on/off of the diodes, the antenna array is made to resonate at multi-band of frequencies. The Array can be configured for multiple frequencies via $5.4 \mathrm{GHz}, 6.2 \mathrm{GHz}$ and 9.2GHz.This array has been configured as a $1 \mathrm{X} 8$ linear array with inter element spacing of $0.53 \lambda$. This spacing is chosen to avoid grating lobe while scanning $\pm 45^{\circ}$. The array gain is $11 \mathrm{~dB}$ to $18 \mathrm{~dB}$ which is reconfigurable over the frequency. The VSWR is 2: $1(\max )$. Linear array HPBW is $\pm 8^{\circ}(\mathrm{Az})$ and $\pm 35^{\circ}$ (El). The side lobe level is $-13 \mathrm{~dB}$ as the amplitude distribution is uniform. This antenna has been designed for Liner vertical polarization.

\section{GEOMETRY OF SINGLE ELEMENT}


Figure.1Shows a typical Single element antenna structure, consists of nine Micro-strip Patch elements and Switching networks (08 Nos. of PIN diodes). The single element structure consists of 9 rectangles and 8 switches. Each radiating rectangle has the same substrate. Separate silicon substrates for each rectangle can be used to allow them function independently. The first rectangle connects through 4 switches to 4 other rectangles. Depending on which rectangle is radiating and the switches that are on, that particular equivalent circuit is active.

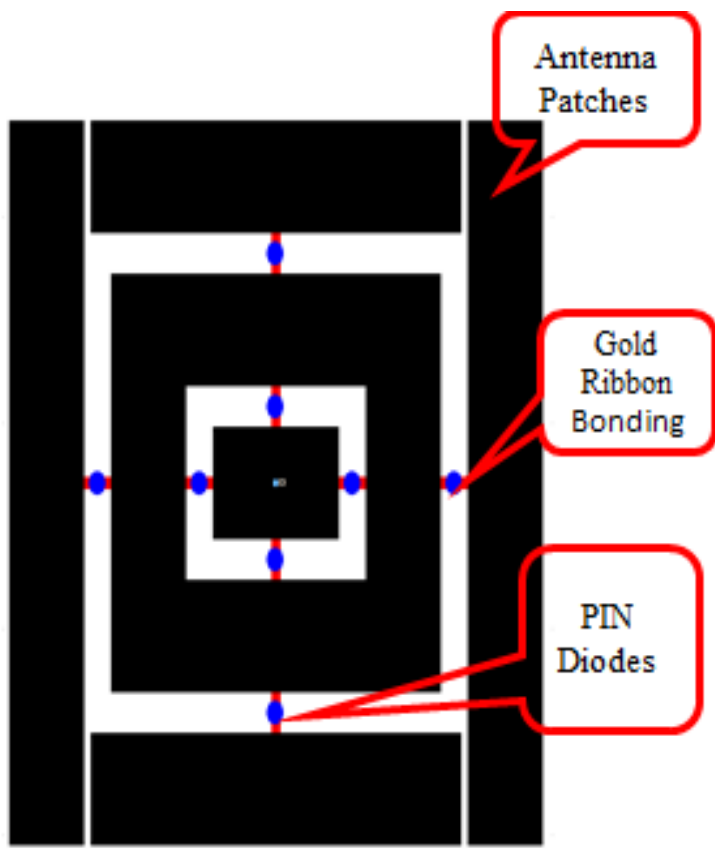

Figure 1. Structure of Single Reconfigurable Antenna

\section{SIMULATION RESULTS}

The Linear Array has been simulated in Three different iterations those iterations as follows

- When only the first rectangle is radiating in each element of the array it is known as the First Iteration. It is the central element of the single element structure with all PIN diodes is in 'OFF' state. When excited, it is observed that the structure resonated at 9.25 GHz as shown in Fig.3.

- When the first four switches are on in single element Structure, it is the Second Iteration. In the second iteration, the inner five numbers of rectangles of each element of the array are radiating, it is observed that the structure resonated at $6.25 \mathrm{GHz}$ as shown in Fig.4.

- When all the 8 PIN diodes are 'ON', it is the Third Iteration. The switches connecting the central element with the other 8 elements are simulated as perfect electric conductors, The ADS MOM Layout as shown in Fig.2. When the central element is excited and the second four PIN diodes are also switched 'ON', it is observed that the structure resonated at 5.325 GHz as shown in Fig.5.
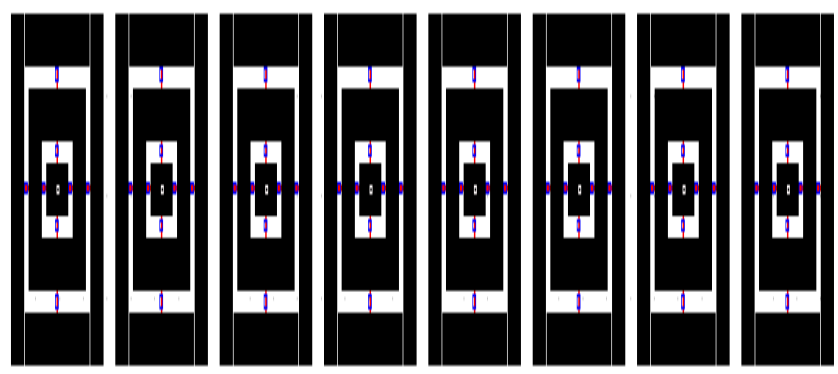

Figure 2. ADS MOM Layout of $1 \mathrm{X} 8$ Linear Array in $3^{\text {rd }}$ iteration

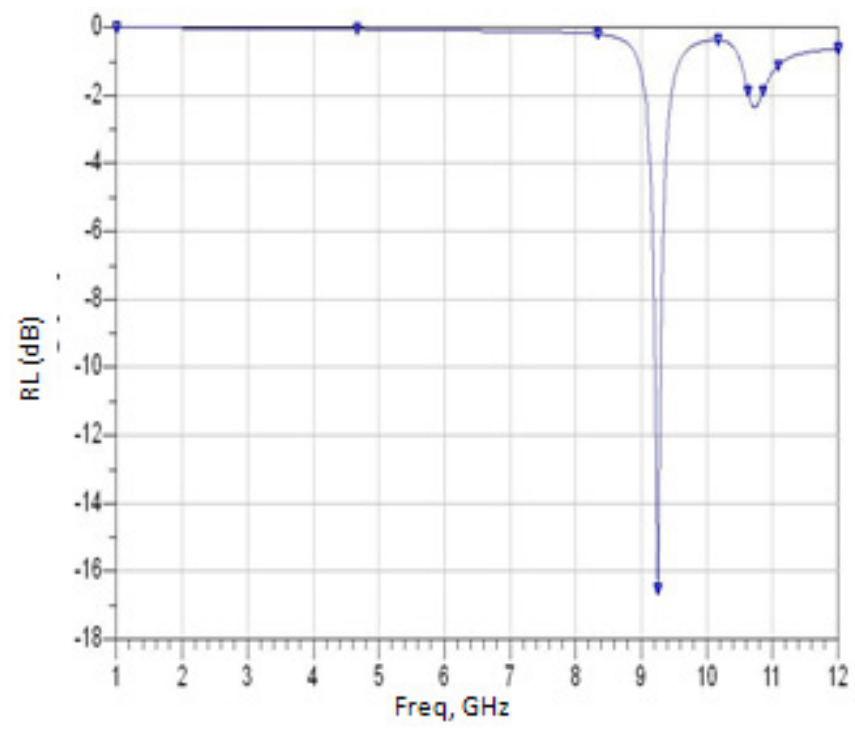

Figure 3. Return Loss obtained for antenna Array in the $1^{\text {st }}$ iteration

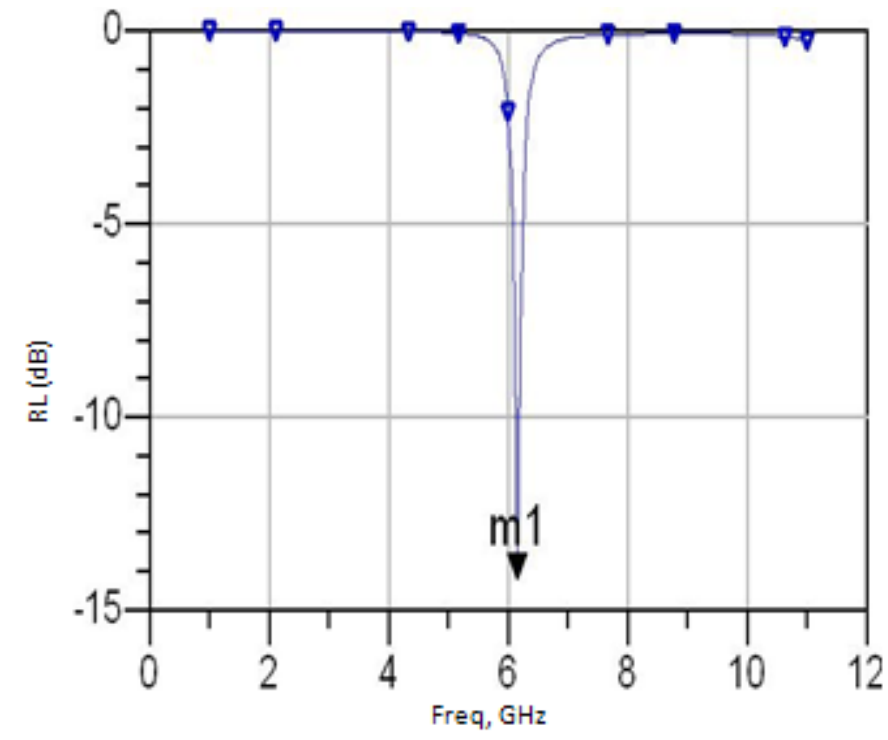

Figure 4. Return Loss obtained for antenna Array in the $2^{\text {nd }}$ iteration 


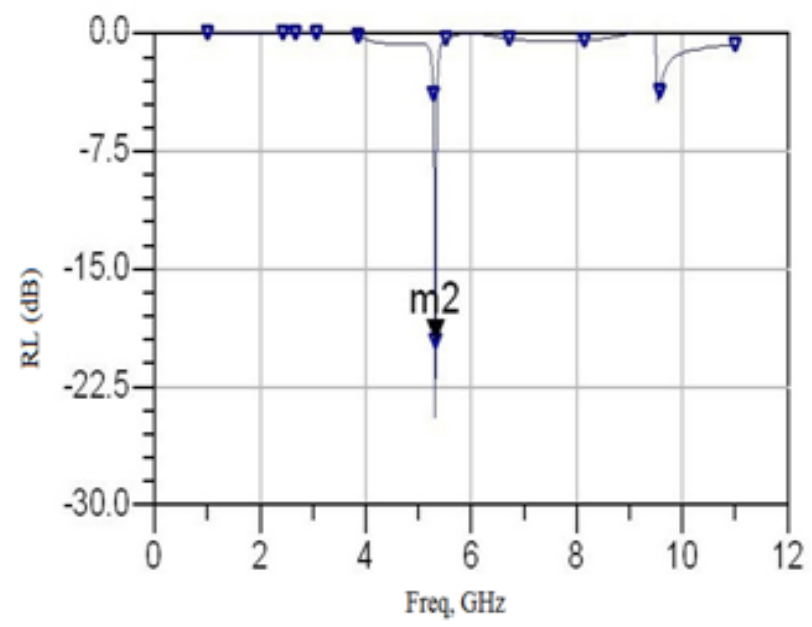

Figure 5. Return Loss obtained for antenna Array in the $3^{\text {rd }}$ iteration

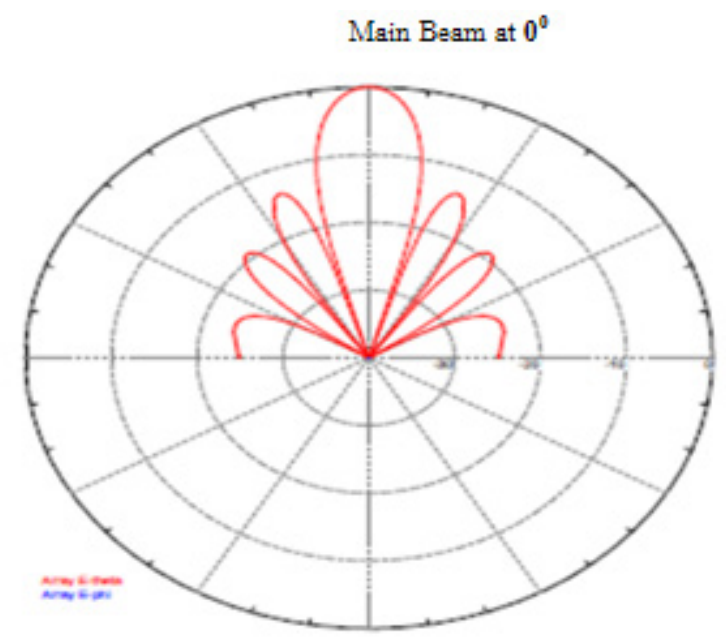

Figure 6. Radiation Pattern of $1 \mathrm{X} 8$ Array during $1^{\text {st }}$ Iteration

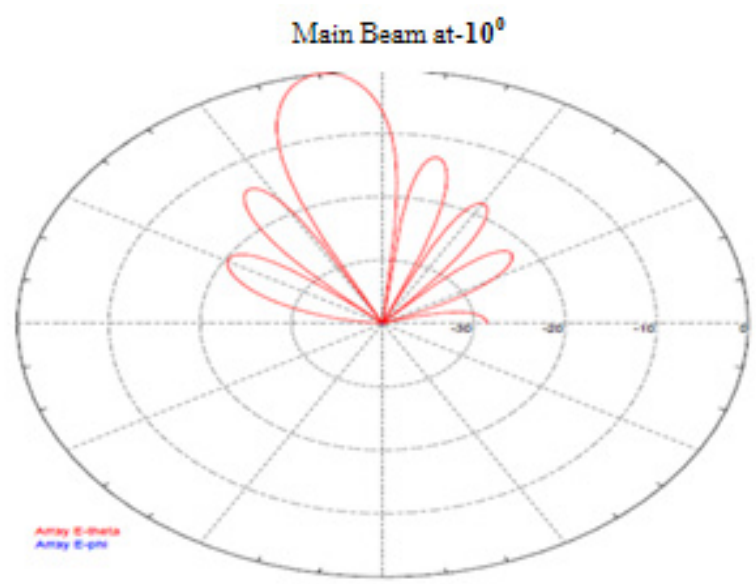

Figure 7. Radiation Pattern of $1 \mathrm{X} 8$ Array during 2nd Iteration

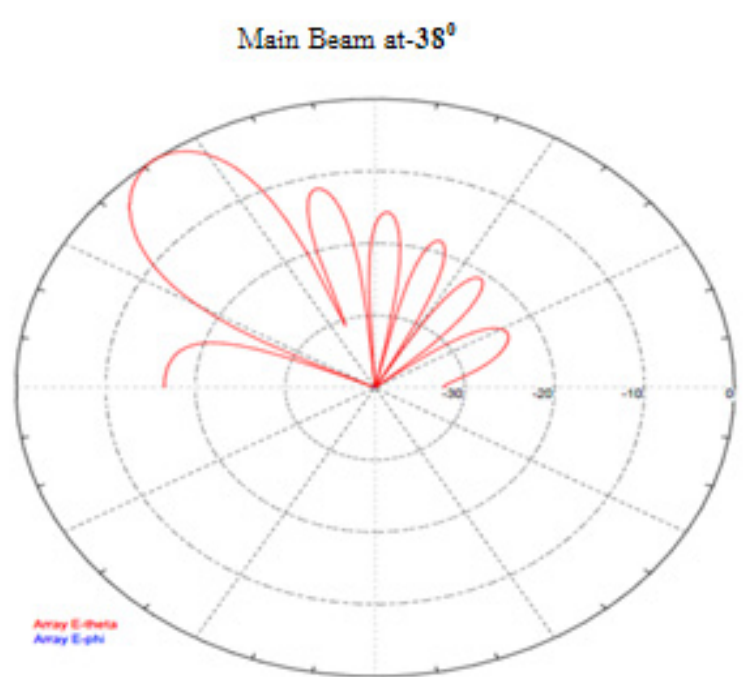

Figure 8. Radiation Pattern of $1 \mathrm{X} 8$ Array during $3^{\text {rd }}$ Iteration

The Figures 6 to 8 Show the Radiation Pattern of Linear array when it excited in iteration 1,iteration 2 and iteration 3 respectively with uniform distribution and it is observed that in the $1^{\text {st }}$ iteration main beam is at $0^{0}$,in the $2^{\text {nd }}$ iteration main beam at $-10^{0}$ and in the $3^{\text {rd }}$ iteration main beam at $-38^{0}$.

\section{MEASURED RESULTS}

The designed Antenna Array has been fabricated using photolithography process and the photographs are shown in the Fig.9 and Fig.10. Fig.11Shows the Return loss Measurement Setup with Vector Network Analyzer, While measuring the Antenna array instead of PIN Diodes when diodes are in $\mathrm{ON}$ states metallic strip length of $1.0 \mathrm{~mm}$ and width of $1.0 \mathrm{~mm}$ are used When the diodes are in OFF states, metallic strips were removed from the geometry leaving the gap of $1.0 \mathrm{~mm}$.

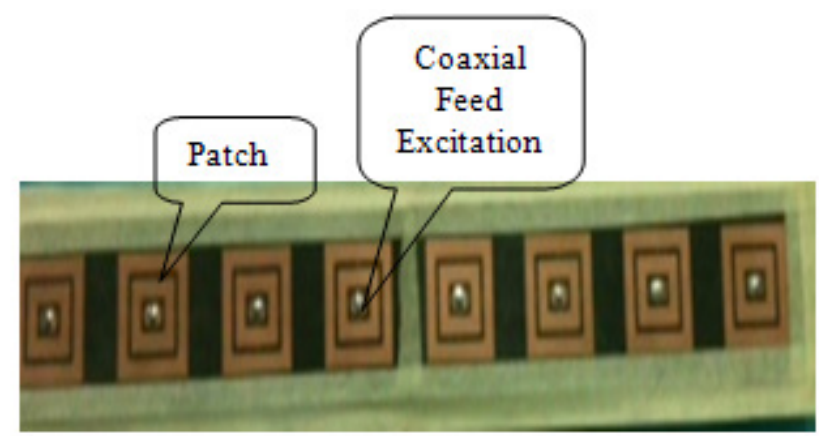

Figure 9. Photograph of Fabricated Array (Front View) 


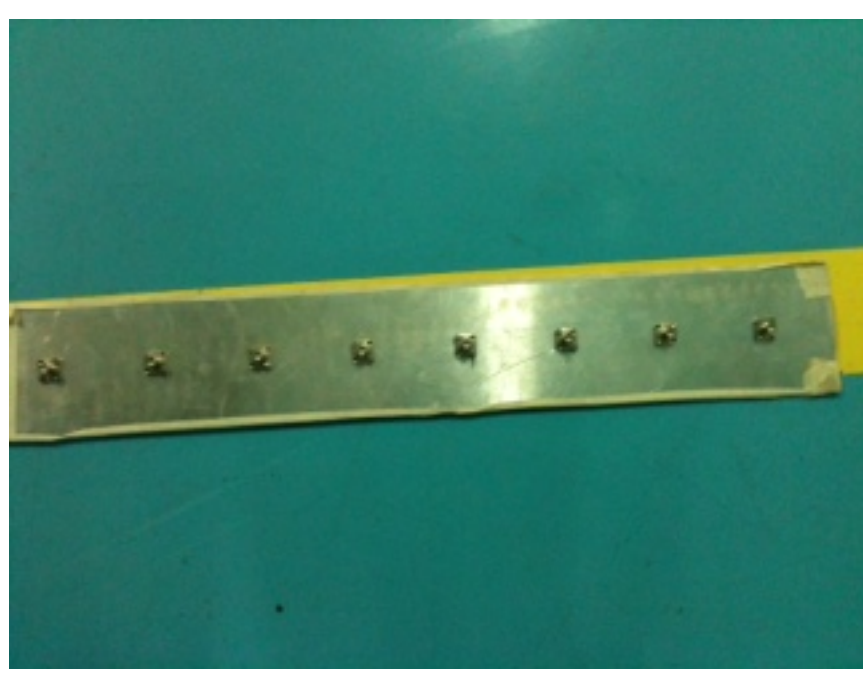

Figure 10. Photograph of Fabricated Array (Rear View)

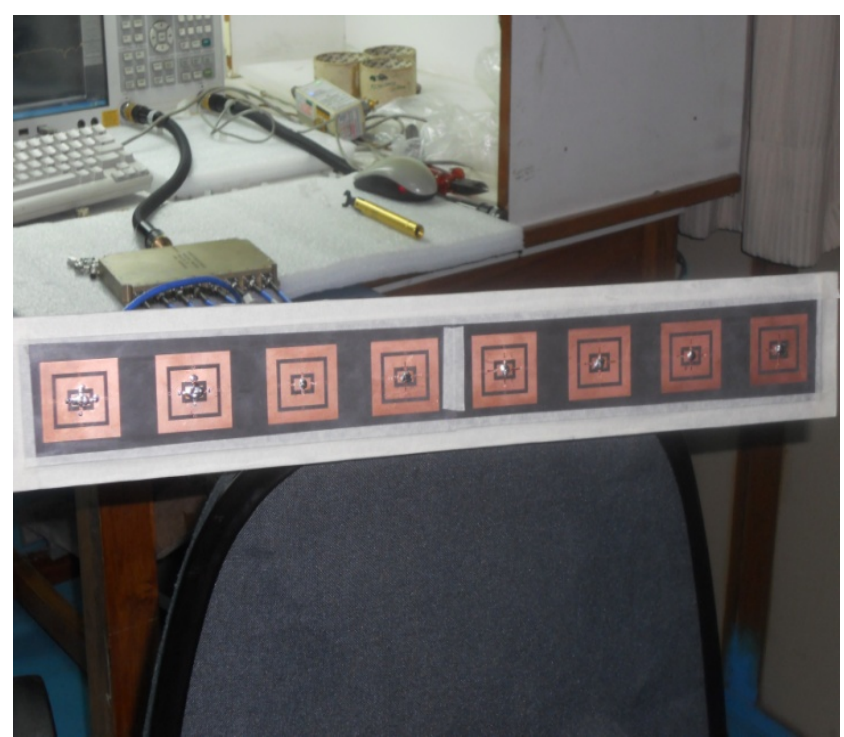

Figure 11. Photograph of Return Loss measurement Setup

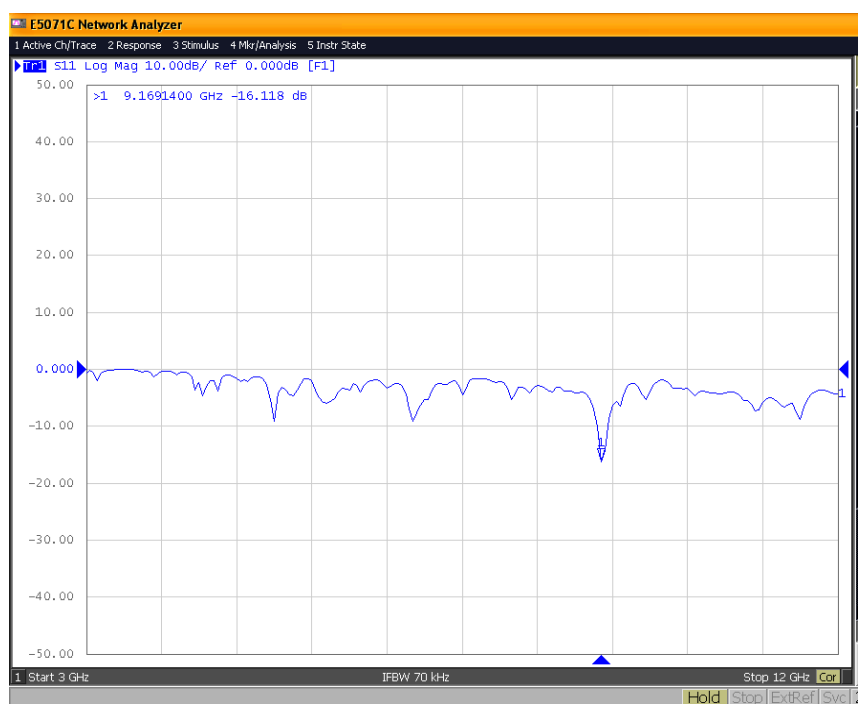

Figure 12. Measured Return Loss obtained in the $1^{\text {st }}$ iteration

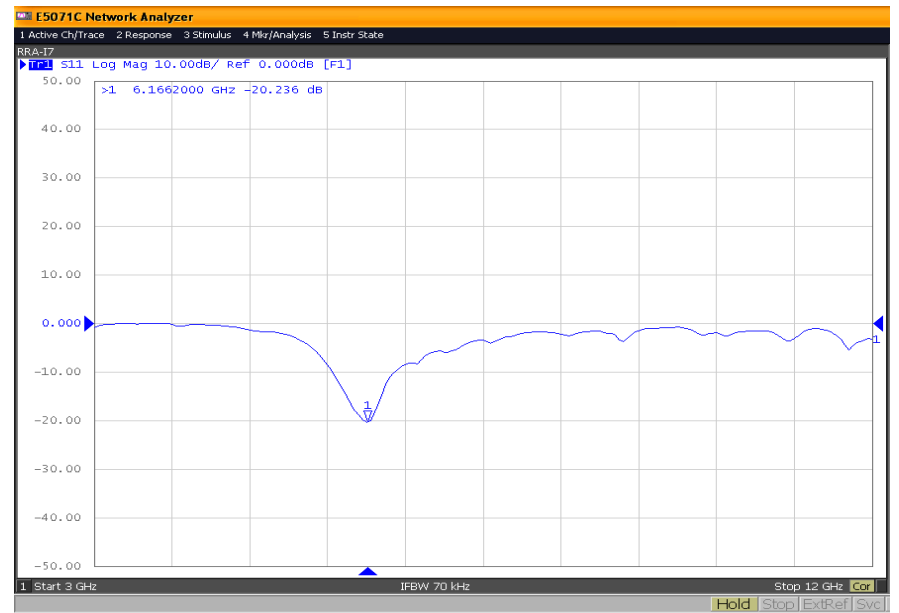

Figure 13. Measured Return Loss obtained in the $2^{\text {nd }}$ iteration

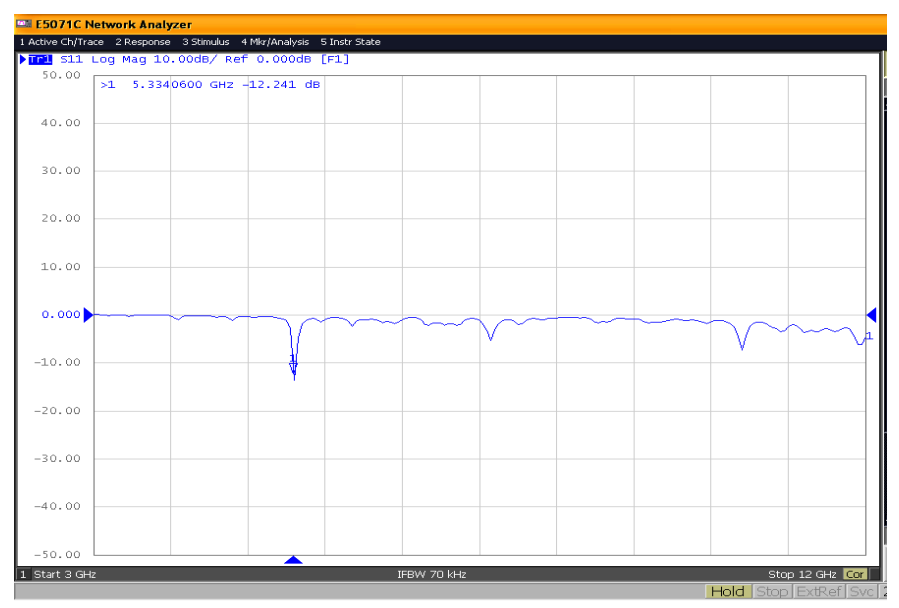

Figure 14. Measured Return Loss obtained in the $3^{\text {rd }}$ iteration

The Figures 12 to 14 show the measured return loss of an antenna array in $1^{\text {st }}, 2^{\text {nd }}$ and $3^{\text {rd }}$ iterations. The Figures 15 and 16 show the Radiation pattern measurement setup in outdoor environment. Figures 17 and 18 show the measured patterns when the Antenna array existed with uniform distribution when the array in $1^{\text {st }}$ and $3^{\text {rd }}$ iteration respectively. Table I gives the comparison between simulation and measured results in the three different iterations.

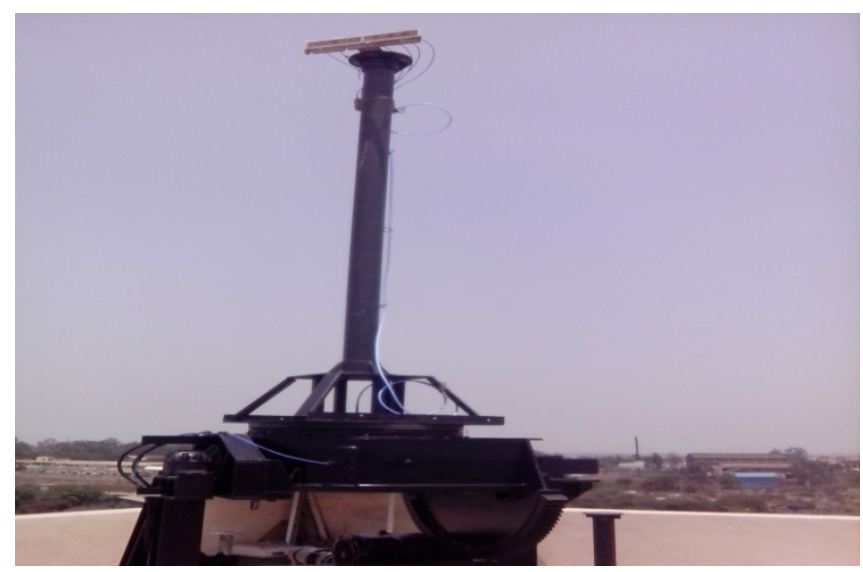

Figure 15. Photograph of Pattern measurement Setup 


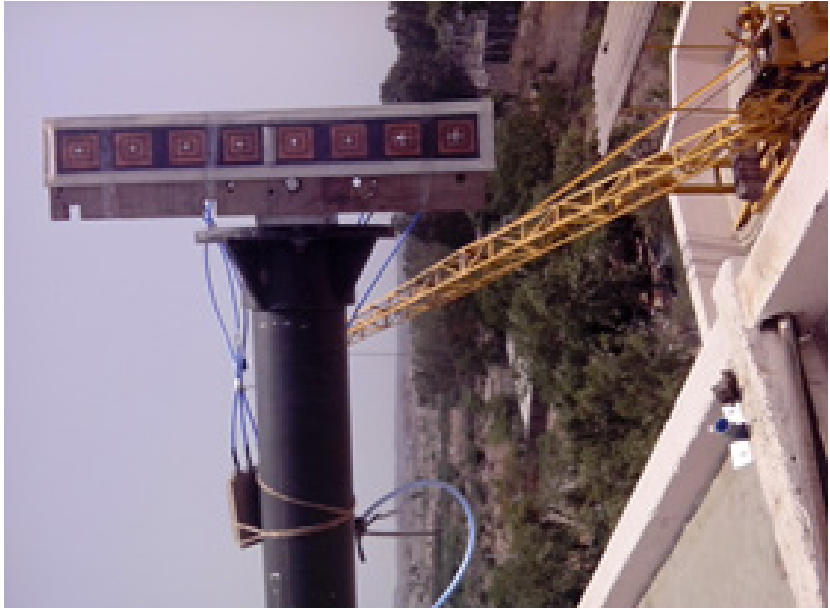

Figure 16. Antenna on Positioner

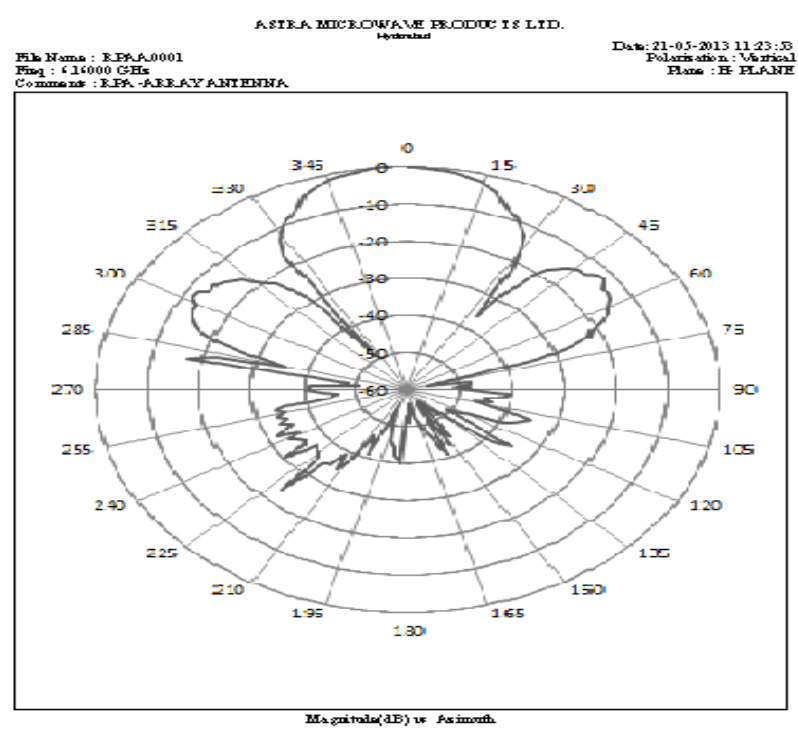

Figure 17. Measured Pattern of $1 \mathrm{X} 8$ array during $1^{\text {st }}$ Iteration

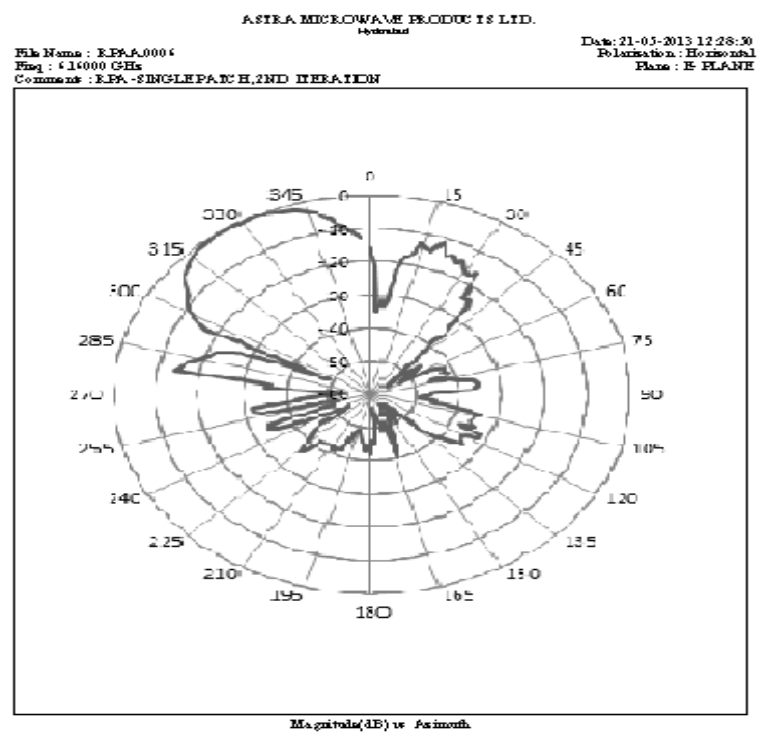

Figure 18. Measured Pattern of $1 \mathrm{X} 8$ array during $3^{\text {rd }}$ Iteration
Table 1. Comparison Of Simulation and Mesured Results

\begin{tabular}{|c|c|c|c|c|c|c|}
\hline \multirow{2}{*}{ Parameter } & \multicolumn{2}{|c|}{ Simulation Results } & \multicolumn{3}{c|}{ Measured Results } \\
\cline { 2 - 7 } & \multicolumn{2}{|c|}{ Frequency(GHz) } & \multicolumn{3}{c|}{ Frequency(GHz) } \\
\cline { 2 - 7 } & \multicolumn{2}{|c|}{ ITERATION } & \multicolumn{3}{c|}{ ITERATION } \\
\cline { 2 - 7 } & I & II & III & I & II & III \\
\hline Frequency(GHz) & 9.25 & 6.15 & 5.32 & 9.16 & 6.16 & 5.33 \\
\hline Gain(dBi) & 12.4 & 15.9 & 14.9 & 12.3 & 15.5 & 15.5 \\
\hline $\begin{array}{c}\text { Beamwidth(Az) } \\
\text { in degrees }\end{array}$ & 8.6 & 9.5 & 8.9 & 8.7 & 9.3 & 9.2 \\
\hline Returnloss(dB) & -16 & -14.2 & -19.5 & -16.1 & -20.2 & -12.2 \\
\hline
\end{tabular}

\section{Conclusion}

In this paper pattern reconfigurable printed linear array antenna using PIN Diodes has been designed and fabricated. This antenna can be used for multiband applications. The simulated results are in good agreement with the measured results. Though these results were slightly differing, it can easily be improved by increasing the fabrication accuracy of the designed antenna array.

\section{ACKNOWLEDGMENT}

The authors wish to gratefully acknowledge Centre for Excellence in Microwave Engineering (CEME) of Osmania University and Astra Microwave Products Pvt.Limited-Hyderabad-India for providing the facilities.

\section{REFERENCES}

[1] R. L. Haupt and M. Lanagan, "Reconfigurable antennas,"IEEE Antennas Propag. Mag., vol. 55, no. 1, pp. 49-61, 2013.

[2] Shisghir Shankar Punjala,Kia Makki "Rectangular Reconfigurable Antenna(RRA) with Ultra Wideband Tuning Ability"3rd European Coference on Antennas and Propagation,2009(EuCAP2009),pp422-423.ISBN:978-3-00024573-2.

[3] Loizeau. S, Sibille. A, "A Reconfigurable PIFA Antenna with Ultra wideband Tuning", Antennas and propagation,2007, EuCAP 11-16 Nov. 2007, pp 1-6, ISBN: 978-0-86341-842-6.

[4] N. Behdad and K. Sarabandi, "Dual-Band Reconfigurable Antenna with a Very Wide Tunability Range,"IEEE Transactions on Antennas and Propagation, Vol. 54, No.2, February 2006, pp.409-416.

[5] Songnan Yang, Chunna Zhang, Helen K. Pan, Aly E. Fathy, and Vijay K. Nair "Frequency-Reconfigurable Antennas for Multi radio Wireless Platforms" IEEE Microwave Magazine, February 2009.

[6] J. Boerman and J. Bernhard, "Performance study of pattern 
reconfigurable antennas in MIMO communication systems," IEEE Transactions on Antennas and Propagation, vol. 56, no. 1, pp. $231-236,2008$.

[7] Haider, N., Tran, D.P., and Yarovoy, A.G.: 'A new concept for frequency reconfigurable phased-array element'. Loughborough Antennas and Propagation Conf., November 2011.
[8] S.-J. Ha andW. Jung, "Reconfigurable beam steering using a microstrip patch antenna with a u-slot for wearable fabric applications," IEEE Antennas Wireless Propag. Lett., vol. 10, pp. 1228-1231, 2011. 